mind of an individual which may be drawn from a study of his or her handwriting.

\author{
(Vol. 8, 1903, No. 8, April 20.)
}

I. The Patellar Reflex in Neuroses. L. Schyyder.

2. Dolorific Assymetry. J. Ioteyko and M. Stephanow'ska.

I. Patellar Reflex.-The author calls attention to the extreme difficulty in securing relaxation of the limb when examining the condition of the patellar reflex in nervous subjects, the patients usually seeming unable to keep from contracting either the extensor or the flexor muscle of the leg. $\mathrm{He}$ regards this as constituting a symptom of some value as indicating nervous irritability, and compares its method of production with that of the muscular rigidity found in myotonia congenita, in catalepsy, and the negativism of certain mental diseases, and in hysterical contraction. To illustrate his views he gives short clinical histories of ten patients suffering from neurasthenic, hysterical and mild mental symptoms, in whom this phenomenon was present.

2. Dolorific Assymetry.-It has long been known that there is a difference in general sensibility upon the two sides of the body, greater upon the right in right-handed persons, and upon the left in left-handed ones. Van Biervliet has shown that the proportion is usually as to to 9. Starting out from the above facts, and from the researches of Goldscheider and Von Frey, which seem to show proof that there are special nerve fibers, respectively tor pressure, for pain, and for temperature sense, the authors carried on a series of experiments with a view of ascertaining if there is any difference in the acuteness of the pain sense upon the two sides. In their measurements they made use of the algesimeter of Chéron. Their experiments were performed upon $\mathbf{5 2}$ subjects, mainly university students, fourteen of this number being left-handed. 'The points chosen for pricking by the instrument were exactly symmetrical areas on the anterior surfaces of each forearm, just above the wrist. The following are the results obtained: Two of the subjects were practically insensible to pain. Of the remaining fifty, three persons showed greater sensitiveness npon the right side, but in two of these even, the result was doubtful. All of the remaining forty-seven showed greater sensibility to pain upon the left side, both right-handed and lefthanded persons being included in the number. Taking the average of the elgesimeter readings for all of these, the sensibility of the two sides was found to be as 10 to 9 in favor of the left conforming to the figures of Van Biervliet. Experimenting upon other regions (the finger tips, back of the hand, temples), the authors still found sharper pain sense in these cases always on the left. They make no attempt to explain the cause of the difference.

C. L. AlL.eN, Trenton.

\title{
PSYCHIATRISCHE, NEUROLOGISCHE, WOCHENSCHRIFT
}

\section{(Vol. 4, 1903, No. 48.)}

The Trcatment of Epilepsy According to the Toulouse-Richet Method. - Halmi and Bagarus. Fifteen cases of epilepsy which had been under observation in the hospital for some time were selected for the investigation. For ten months these patients were treated with 3-5 gms. of bromide daily, then followel two months without any medicinal treatment, at the end of which time the Toulouse-Richet method of treatment was applied for one month. During the first half of this period $3 \mathrm{gms}$. of bromide were given, when the dosage was reduced to 1.5 gms. ; diet consisting of 2 litres of milk, 2 eggs, and for the men $750 \mathrm{gms}$, for the women 500 gms. of salted bread. Following this period of treatment they returned to the simple bromide treatment. In view of the great variation in the number of attacks monthly during treatment with simple bromides-in one case 
19-3I, in another 3-IOH attacks, it would seem manifestly unfair to accredit a cure unless there was improvement in a large majority of the cases. Furthermore, in the nine months without change of treatment, nine cases showed spontaneous improvement. During the two months when the bromides were withdrawn the attacks increased in seven and diminished in three cases, and two patients died, but the total number of attacks fell to 273, or nearly one half of the total number in the two months when the bromides were withdrawn. Still, during six of the ten months in which the simple bromides were given, the total number of attacks was less than during the test month. Furthermore, a close study of the individual cases which seemed most improved reveals the fact that just as great improvement had previously occurred during the treatment with the simple bromides. In the final period of seven nonths the total number of attacks in the thirteen remaining cases rose to 324 , but later fell to 219 , in spite of the fact that the bromides were entirely withdrawn in five cases. Besides this doubtful effect in the number of the convulsions, this method of treatment had an appreciable sedative infuence upon all psychical proccsses. The patients were less restless and exhibited a retardation which, in some cases. almost reached genuine stupor. In two cascs it produced a fatal intoxication. In conclusion, the Toulouse-Richet method ncither cures nor henefits, and greatly enhances the danger of bromism.

(Vol. 5, 1903. No. I.)

The author (Waltenberg), after citing the theoretical and practical reasons for the abolishment of the "isolation cell" in the treatment of naniacal patients, presents the results accomplished during the past six years ( $1896-1902$ ) at Lübeck, by the substitution of the constant watch, and the prolonged bath. He observes that during this period a greater degree of quiet prevailed, and there was a proportionate less demand for narcotics. The plotted curves accompanying his paper show the gradual fall of the percentage of women reported restless at night (1I.3 per cent to 3.2 per cent), and a similar fall in the use of narcotics ( 3.6 per cent to 1.2 per cent).

(Vol. 5, 1902, No. 2.)

The Prognosis and Therapy of Intemperance. SAUERMANN-Bons.

The author calls attention to the increasing prominence of institutions for the treatment of inebriates, the reports of which record from $15-80$ of recoveries, to the prominent role played by the "after treatment" in the third conference of the German inebriate institutions, and cites the method instituted at the Swiss Institution Ellikon by the establishment of a society of discharged patients for the purpose of mutual aid in maintaining abstinence. Their results are 70 per cent of recoveries from $1896-1900$. His statistics relative to the prognosis are based upon 246 replies from members of the Red Cross Abstinence Society. He concludes (I) that recovery from alcoholic intemperance is synonymous with prolonged abstinence; (2) the frequency of defective heredity and a psychopathic constitution has led to the belief that a large number of alcoholics are incurable. The real basis for this belief lies in a lessened resistance to the action of alcohol; the drink custom and other accompanying influences only give opportunity. The patient cannot be cured of hereditary intolerance, he can only be freed from alcohol. Recovery from acquired intolerance is possible. (3) The necessity of prolonged abstinence and the great tendency to relapse demands prolonged attention after dismissed from treatment. (4) Secret abstinence societies are well adapted to exercise this extended cure. They not only prevent but lessen the danger of relapse. (5) Temperance abstinence societies should affiliate with public institutions for the treatment of alcoholics. (6) The fact that abstinence can be secured without institutional treatment will make it possible in many cases to shorten the time of treatment now prescribed (from six to twelve months). In spite of these re- 
sults he believes that in the majority of cases institutional treatment is necessary. In this treatment, employment of the patients is essentual for their betterment, and conduces to economy in their support at the institution. DeFEn DORF (Middleton, Conn.).

\section{ARCHIVES DE NEUROLOGIE \\ (Vol .XV, I903, No. 88, April.)}

I. Historical and Critical. Physio-psychology of Women in Religious Orders; the Nuns of Port Royal (Fifth Series of Five Observations). Charles Brner-Sangle.

2. Upon Some Clinical Particularities of Facial Neuralgia and Its Treatment by Electricity. A. ZIMMERN.

3. Fibromatose and General Paralysis. Dr. A. Cullerre.

I. Women in Religious Orders, ctc.-The author presents an interesting study (to be continued) of the lives and mental and physical experiences of three nuns of the famous convent of Port Royal, since destroyed (near Paris, France). The facts are obtained from various historical, biographical and statistical works cited by the author, and the study carries us back to the year I66I, the time of the Jansenist controversy, when the nums, upon pain of dismissal to other and, in the Catholic sense, orthodox communities, were required to sign a "formulary" condemning certain five propositions contained in Jansen's treatise upon the theology of St. Augustine. When we consider that the propositions were upon such subjects as Free Will, Divine Grace and Predestination, we cannot wonder that the sisters. who had sought rest for their souls behind the convent veil. should have been driven into torment of mind, when compelled to decide whether they were bound in conscience by the decision of the church on those subjects, while in their own understanding, they held different views. Under stress, some would sign, and thereupon be seized with mental torture, dreading the fate promised to liars and hypocrites. Mind acted on body and aggravated physical maladies. The author, after stating at much length the story of fifteen years of bodily illness and of occasional moral suffering, in the life of the nun Margarite Dupré, and relating particularly an account given of her entire relief, in answer to a special prayer, from all her bodily illness for three months, makes the following summary of her case.

Character.-Haughty and of a "nature prompt and lively," she bacame under the influence of religious suggestions, reserved, quiet and humble. She called herself "a poor ignorant" and busied herself with labors to the most lowly.

Sadness.-She exhibited a predisposition to sadness. In I66I, dysentery dcclared itself upon an occasion of mental distress. In 1662 her abscesses of the liver were accompanicd "with great spiritual suffering." In I664, during her exile to the "Anonciades of S t.Denis," the news that certain nuns of Port Royal had signed the formulary plunged her into dejection. Herself urged by the archbishop of Paris to surrender. "she passed five days in weeping, in despair of her condition, distracted between the fear of offending God in signing and having always to suffer for not signing," "in pain and transported with agony." She finished by submitting and gained only ncw disquietude. The day of her return to Port Royal, she remained in a corner of the church "praying and weeping." At that time "she slept little at night." Finally, being convinced that the signature was a wrong act, she accused herself of her fault "in terms most humble and most touching and with great abundance of tears." "From that moment she felt the greatest joy that she had ever experienced, mingled with heartfelt grief for her sin." She continued to deplore it and had frightful remorse on account of it.

Suggestibility.-She said à propos of the pseudo miraculous, as the 